\title{
Amb quins criteris el professorat valora un projecte d'innovació de física en context?
}

\author{
Luisa Herreras Blanco \\ IES Guillem de Berguedà (Berga) \\ Lherrer1@xtec.cat
}

L'objectiu principal d'aquest treball ha estat investigar amb quins criteris el professorat valora l'aplicació d'un projecte de física en context, analitzant la seva contribució al desenvolupament de les capacitats recollides en les finalitats i els objectius del batxillerat.

Paraules clau: ciència en context, física, CTS, SHAP, innovació educativa, valoració

\section{PER QUÈ AQUESTA INVESTIGACIÓ?}

És un fet generalitzat el descens del nombre d'alumnes matriculats en la modalitat de ciències a batxillerat $i$, en particular, en la matèria de física. Com a conseqüència, encara és menor el dels que arriben a realitzar estudis posteriors en aquesta branca. Una de les raons d'aquesta davallada sembla ser la distància entre el currículum que s'ofereix a l'alumnat i el seu entorn. A l'alumnat li costa trobar el sentit de tot allò que se li ensenya. Una resposta que es dóna a aquest problema és la de desenvolupar currículums Ciència-TecnologiaSocietat (CTS). En aquesta línia, el projecte de física en context adaptat de l'anglès SHAP en el marc del CDEC, s'experimenta a Catalunya des de l'any $2004 \mathrm{i}$, actualment, per més de quaranta professors i prop d'un miler d'alumnes.

La investigació aquí iniciada forma part d'un procés que, després de dos anys d'experimentació al meu centre de treball, ha desembocat en l'estudi de què ha significat la seva aplicació en la pràctica educativa, a fi i efecte de reflexionar sobre aquesta classe d'innovació i d'avaluar les seves implicacions en el context escolar.

Per tant, el seu objectiu sorgeix de la pròpia pràctica educativa, emergint del discurs del professorat experimentador.

L'objectiu fonamental d'aquest treball ha estat identificar i analitzar alguns factors que influeixen en l'aplicació d'un projecte innovador de física en context per al batxillerat i les seves fortaleses i fe- bleses a fi de plantejar propostes que serveixin per millorar-lo i generalitzar-lo.

Concretament, ens ha interessat el punt de vista del professorat que l'aplica i també el dels experts en didàctica sobre factors relacionats amb:

- El currículum associat al projecte: Què se'n valora i amb quins arguments, com l'aplica el professorat implicat, com troben que s'adapta a les exigències de les proves de selectivitat i si perceben que és susceptible de millora.

- La formació rebuda i la seva influència en canvis personals o en l'entorn immediat: Què motiva al professorat experimentador a aplicar-lo, quins impactes metodològics, tecnològics $\mathrm{i}$ didàctics ha rebut sobre la seva pràctica i el seu entorn i quin ha estat l'impacte sobre l'alumnat.

- Les accions per millorar el projecte i difondre la seva aplicació: Què s'hauria de millorar, per què i com, i amb quines estratègies es pot realitzar la difusió d'aquesta innovació a altres professionals de l'ensenyament.

\section{COM HEM TREBALLAT?}

Hem desenvolupat una investigació en part descriptiva -ens aproxima al coneixement de la realitat que hem estudiat-, però també interpretativa, doncs dóna explicacions d'aquesta realitat per saber com interpreten els professors les situacions, què signifiquen per a ells, quines intencions tenen, 
etc. Ens ha permès, a més, descriure, comprendre i explicar l'aplicació de l'adaptació del Projecte Salters en el seu context, des de la perspectiva dels ensenyants. Es tracta també, per tant, d'una investigació subjectiva, doncs reflecteix el punt de vista del professorat.

\section{QUINS HAN ESTAT ELS PROTAGONISTES?}

La població de la recerca està constituïda per tot el professorat relacionat amb el projecte, és a dir, experts en el camp del disseny de projectes innovadors per a l'ensenyament de les ciències, professorat adaptador del projecte original anglès i professorat experimentador.

En el cas de l'instrument principal utilitzat per recollir dades, l'entrevista, varem triar una mostra de 8 professors:

- professor responsable del disseny del projecte, així com de l'organisme que fa de suport de tot el procés d'aplicació (A1)

- especialista en didàctica de la física (A2)

- professor especialista en projectes d'innovació, en formació del professorat, adaptador i experimentador del projecte (C1)

- professor coordinador, adaptador i experimentador del projecte (C2)

- professorat experimentador del projecte (B1D, $\mathrm{B} 1 \mathrm{R}, \mathrm{B} 2, \mathrm{~B} 3$ )

Aquesta informació està resumida a la taula 1.

\section{QUÈ HEM UTILITZAT?}

Els dos instruments més potents de la recerca han estat l'entrevista i l'observació a l'aula del professorat vinculat al projecte. A més, hem utilitzat els materials de l'adaptació catalana del projecte i de l'original anglès, les fitxes de valoració de les activitats del projecte redactades pel professorat experimentador, les intervencions als fòrums de la plataforma Moodle del CDEC i els qüestionaris passats en diferents cursos al professorat experimentador.

Pel que fa a les observacions d'aula, el seu objectiu era entendre el context en que tenia lloc l'aplicació del projecte observant-lo directament. Ens han permès recollir informació no explicitada a les entrevistes al mateix temps que ens servien per aclarir aspectes que d'altra manera haurien estat difícils d'entendre.

La nostra pretensió era d'interpretar l'aplicació del projecte d'innovació mitjançant una "fotografia" feta en diferents moments i a diferents professors.

\begin{tabular}{|l|c|c|c|c|}
\cline { 2 - 5 } \multicolumn{1}{c|}{} & $\begin{array}{c}2005- \\
\mathbf{2 0 0 6}\end{array}$ & $\begin{array}{c}2006- \\
\mathbf{2 0 0 7}\end{array}$ & $\begin{array}{c}\text { 2007- } \\
\mathbf{2 0 0 8}\end{array}$ & $\begin{array}{c}\text { Comarca } \\
\text { de l'IES }\end{array}$ \\
\hline B1D & Primer & Segon & Primer & $\begin{array}{c}\text { Vallès } \\
\text { Occidental }\end{array}$ \\
\hline B1R & & Primer & Segon & $\begin{array}{c}\text { Vallès } \\
\text { Occidental }\end{array}$ \\
\hline B2 & & Primer & $\begin{array}{c}\text { Primer i } \\
\text { Segon }\end{array}$ & $\begin{array}{c}\text { Vallès } \\
\text { Occidental }\end{array}$ \\
\hline B3 & Primer & Primer & $\begin{array}{c}\text { Primer i } \\
\text { Segon }\end{array}$ & $\begin{array}{c}\text { Vallès } \\
\text { Occidental }\end{array}$ \\
\hline B4 & Primer & $\begin{array}{c}\text { Primer i } \\
\text { Segon }\end{array}$ & $\begin{array}{c}\text { Primer i } \\
\text { Segon }\end{array}$ & Bages \\
\hline C2 & Primer & & Primer & Barcelonès \\
\hline
\end{tabular}

Taula 1. Informació sobre el professorat experimentador observat

Aquesta informació ens permetia triangular les dades obtingudes en les entrevistes i saber com s'aplicava el projecte a l'aula així com copsar la resposta de l'alumnat, aspectes del màxim interès per al nostre estudi.

\section{COM HEM ANALITZAT LES DADES?}

La classe d'estudi que volíem fer pretenia entendre en quina mesura el projecte d'innovació en context ha comportat canvis en la pràctica del professorat -de tot tipus: curriculars (què s'ensenya $i$ com), i personals (de formació...)-, així com quins problemes presenta la seva aplicació i quins avantatges es poden entreveure en relació als supòsits i pràctiques tradicionals. Per això els dos àmbits relacionats amb els dos grans objectius que hem plantejat des de la nostra perspectiva són:

a) Aspectes relacionats amb canvis en el currículum aplicat i materials utilitzats.

b) Aspectes relacionats amb la formació, canvis i incidències dels professors i el seu entorn en l'aplicació del projecte.

Les categories de cadascun d'ells s'han obtingut de manera diferent. El primer àmbit l'hem desglossat en una sèrie de categories descriptives basades en el marc curricular utilitzat en secundària durant la LOGSE i en els materials del projecte que estudiem (Grup Salters, 2006). A mesura que hem analitzat les unitats de significat hem completat les categories amb d'altres que també han resultat necessàries i que inicialment no havíem tingut en compte. 
Les categories del segon àmbit són interpretatives a partir del que hem inferit de les unitats de significat, organitzant-les, posteriorment, segons els canvis produiits en els grups en què es mou cada professor segons el context (personal, departament del centre i centre, grup d'experimentadors, grup classe, CDEC).

Tota l'anàlisi de dades ha estat triangulada per l'investigador a fi de comparar i contrastar els resultats.

\section{QUINS RESULTATS HEM OBTINGUT?}

\section{Aspectes relacionats amb canvis en el currículum i en els materials}

\section{Pel que fa a què s'ensenya}

El que caracteritza aquest projecte com a innovador és precisament l'enfocament contextualitzat dels continguts a través de les aplicacions. És el que es denomina "les aplicacions primer", com constata un professor: "està bé que es donin exemples quotidians dels problemes dels quals es parla, perquè moltes vegades s'ha fet física que no hi havia context i només hi havia fórmules; és evident que això era ja un avanç important."

\section{Pel que fa a com s'ensenya i als materials}

El professorat experimentador expressa les seves reflexions: "costa fer les classes de manera diferent sobretot si tens 30 alumnes".

Alguns professors, els més disposats a seguir fidelment la innovació, s'han trobat que metodològicament les estratègies a aplicar estaven poc definides.

Tot sovint es fa referència a la diversitat d'activitats, que en molts casos es veu com una qüestió positiva: "l'altra cosa que també m'agrada és que hi hagin moltes activitats pràctiques relacionades". Però en canvi també es mostra la seva part negativa de no poder realitzar-les per manca de temps: "de tot el reguitzell d'activitats que hi ha, n'acabes fent molt poquetes".

També troben insuficients les activitats d'ampliació que apareixen al dossier: "sempre porto uns altres exercicis: els exercicis sí que els he de portar de fora; de fora vol dir fulls addicionals i coses d'aquestes, perquè aquí no hi ha pràcticament res".

Ens trobem que el professorat considera que les lectures són massa llargues i, en conseqüència, es fan molt ràpidament o se salten: "de vegades trauria aquelles explicacions tan llargues per arribar a una fórmula que és per aquell tros; per exemple, en lliscant pel pendent que arribes a una determinada fórmula, doncs tot allò jo m'ho salto".
Respecte a la guia didàctica, el professorat troba que és insuficient: "ningú no et diu com ho has de fer; allà hi ha un contingut; però tu no saps si allò ho has de fer llegir als alumnes, si els hi has d'explicar tu; que no sé si és la manera correcta, però un altre ho farà d'una altra manera, però potser s'hauria d'orientar una mica més..."

\section{Pel que fa a quan i on s'ensenyen}

Tots els professors assenyalen la manca de temps com el problema més greu per poder portar a terme aquest projecte.

També plantegen l'augment de temps que els suposa la preparació de les classes per dues raons: haver d'aprendre els conceptes relacionats amb les aplicacions i per la dedicació que han de fer per aprendre el funcionament dels programes que han d'utilitzar a les seves classes i la seva instal-lació als ordinadors que usen: "la falta d'espai $i$ temps per treballar amb els alumnes: el temps que s'ha de dedicar a la seva preparació, tenint en compte que no havia fet treballs amb TIC abans".

Es queixen sovint de la manca d'espais per poder desenvolupar un projecte com aquest amb un munt d'activitats relacionades amb les TIC.

\section{Pel que fa a què i com s'avalua}

La contextualització de les unitats es realitza depenent del temps que es disposi i és a segon on cada professor ha fet més la seva adaptació i on s'ha aplicat menys la filosofia del projecte, ignorant sobretot les lectures introductòries.

Es troba que amb aquesta manera de plantejar el currículum no es fa pensar autònomament els alumnes, perquè només es treballa el cas concret de l'aplicació.

\section{Aspectes relacionats amb la formació, canvis i incidències dels professors i el seu entorn en l'aplicació del projecte}

\section{Motius inicials i grau d'acompliment a l'aplicar el projecte}

Es valora com un aspecte positiu la millora en els resultats de selectivitat respecte a la mitjana dels obtinguts a Catalunya en la matèria de física: "sí, jo del resultat del projecte, si mirem els resultats de la selectivitat $i$ amb l'alumnat que tenia jo l'any passat; vaig quedar contenta; vaig tenir millors resultats que altres anys".

Respecte a la participació de l'alumnat a les classes, el professorat troba que és més activa: "amb la relació amb l'alumnat, sí, van participant una mica més, però costa; així com jo trobo que 
amb la química participen més, amb la física de vegades costa". "De la mateixa manera que et dic que jo vaig començar molt escèptica, em vaig anar entusiasmant a mesura que anava avançant el curs $i$ aquest any ho segueixo. Perquè, per una banda, noto que els alumnes estan molt més enganxats a la classe del que estaven abans".

El professorat valora positivament el canvi que ha suposat l'aplicació del projecte en el seu procés d'ensenyament: "a mi com a professora em provoca un efecte rebot, és a dir, m'està fent fer que les classes a l'ESO les canviii"; "mai tornes enrere: quan fas un projecte mai tornes enrere, sempre et queda alguna cosa encara que potser d'aquí a deu anys ja no ho fem".

\section{Formació del professorat experimentador}

La majoria diu que el primer any va tenir moltes dificultats a l'hora d'organitzar la classe, de desenvolupar-la, de decidir les activitats d'ensenyamentaprenentatge més adients del gran ventall que hi ha..: "aquest era el primer curs que seguia el projecte $i$ al principi em sentia una mica perduda. No veia clara la dinàmica de la classe".

Els professors troben dificultats en els continguts relacionats amb les aplicacions, perquè no són coneguts i no els han utilitzat en el seu ensenyament anterior, demanant més formació sobre les aplicacions que es treballen en el projecte: "el primer any necessites molta formació sobre el context del que s'està parlant"; "cal un bon domini de la matèria per abordar-la d'aquesta manera".

Els professors valoren com a molt positiva la formació rebuda en les reunions mensuals que es realitzen en el CDEC: "per a mi és el que va bé perquè és el que et va donant seguretat cada cop que t'apareix un dubte... va bé poder-ne parlar amb algú que estigui fent el mateix". Encara que de vegades es considera insuficient: "el seguiment amb una reunió al mes de vegades jo crec que és escàs; però és clar, també veig difícil que sigui d'una altra manera".

\section{Incidències i canvis en el professorat}

El fet de començar per les aplicacions suposa canvis en el discurs del professorat: "potser la qüestió abstracta que abans era la primera en la que insistia, ara es queda cada cop més relegada".

La necessitat de generalitzar aquesta manera de treballar també es planteja: "hi ha d'haver un treball a l'ESO perquè la física Salters obtingui més rendiment $i$ els nanos 'disfrutin' més $i$ participin més".

Un objectiu del grup de treball és estendre a més professorat aquesta manera de treballar.

\section{Incidències i canvis en els alumnes segons els professors}

Els professors opinen en general que, quan es contextualitzen les activitats, la física resulta més propera als alumnes i augmenta la seva motivació, però per a alguns professors això incrementa la dificultat de la matèria a l'haver de treballar continguts afegits.

Comenten també que als alumnes els costa fer la transferència d'un cas particular a una generalització dels conceptes: "que d'un cas particular, després els costa molt fer l'abstracció i passar al general".

Molts dels professors expressen que tots els alumnes troben les activitats que es treballen al projecte molt motivadors, però que els que tenen més dificultats els costa poder superar-les.

Els alumnes amb més capacitat troben el significat d'aquesta manera de treballar, però no així els altres que necessiten ajut per poder transferir el seu aprenentatge: "hi ha alumnes fluixos que ho troben a faltar, troben a faltar un resum del tema que els hi aclareixi les quatre idees; està fet per a alumnes bons, els alumnes fluixos van molt perduts"; "arribes a la conclusió que algun alumne es pot sentir més interessat... però no sé si globalment ho estan".

Els professors associen la manca de temps amb menys motivació en l'alumnat del que es podria obtenir amb el projecte per no poder realitzar més activitats pràctiques: "la manca de temps per poder fer la majoria de les activitats experimentals, que és justament el que provocaria més motivació als alumnes".

Amb l'aplicació del projecte es detecten canvis en els sabers adquirits pels alumnes que no s'havien obtingut anteriorment. Un dels aspectes que s'observen és l'augment de capacitat d'argumentació: "si més no, parlen més de física, tenen capacitat d'anar discutint i anar argumentant".

Encara que l'aprenentatge que assoleixen no és el desitjat pel professorat: "l'aprofitament per part de l'alumnat de vegades no és l'esperat, es queden en coses anecdòtiques i no aprofundeixen".

\section{QUINES CONCLUSIONS HEM EXTRET?}

Els resultats mostren que el projecte, d'una banda, interessa i s'adapta al currículum i a les PAU, i és ric pel que fa a activitats i possibilitats d'ensenyament-aprenentatge que ofereix, tot i que no sempre sabem encara utilitzar-les de manera eficient; i de l'altra, genera un procés de formació i intercanvi en el professorat que es valora com a 
molt positiu i que comporta canvis professionals més enllà de l'aplicació del projecte, molt en la línia del treball per competències.

\section{Quines implicacions didàctiques i propostes hem fet?}

Per promoure un projecte d'innovació, no és suficient que el professorat rebi nous materials: s'ha d'aconseguir que els professors participin de forma activa en la construcció dels nous plantejaments didàctics i s'animin a aplicar estratègies d'aula allunyades de les que formen part de la rutina habitual. Per això és molt important la formació rebuda abans i durant tot el procés, així com la interacció contínua de tots aquells que participen en el projecte.

Pel que fa als materials, haurien de completarse els objectius que falten en algunes unitats, i afegir-ne uns altres; també haurien de comprovar-se les competències que es treballen i quines no es contemplen.

El professorat hauria d'interioritzar el canvi per mitjà de la guia didàctica -una guia que hauria de ser millorada, per exemple, amb la inclusió d'activitats de síntesi al final de cada unitat-, i d'una formació més dinàmica, dedicant temps a la reflexió en i sobre la pràctica. També seria desitjable la millora del dossier de l'alumne.

En ser una matèria experimental i tenint en compte les hores de treball amb ordinadors, el nombre d'alumnes no hauria de ser gaire elevat, única manera de facilitar el treball d'aula.

Proposem, per últim, que es revisi la prova d'accés a la universitat d'aquesta matèria, ja que la considerem allunyada del que es requereix pels estudis subsegüents que s'haurien de valorar molt més les estratègies i els sistemes d'adaptació que desenvolupa l'alumne que centrar-se estrictament en resultats mesurats únicament pels continguts conceptuals.

Afegirem com a implicació que els canvis que comporten les innovacions han de ser generals, afectant a tots els professors i en totes les etapes de l'ensenyament. Si no es fa d'aquesta manera, aquests canvis només constituiran un parèntesi en un moment i un lloc determinats, sense gaire transcendència per a l'alumnat.

\section{Quines altres implicacions ha tingut la investigació?}

Aquest treball està servint com a base d'una investigació que han iniciat dos companys del grup de professors aplicadors del projecte del CDEC i que té com a objectiu el disseny de materials adaptats al nou currículum de física de batxillerat de la LOE.

\section{BIBLIOGRAFIA}

CAAMAÑO, A., PUEYO, L., ENRECH, M., PONT, J. \& PLANA, O. (2005). La física Salters: un proyecto para la enseñanza contextualizada de la física en el bachillerato. Alambique, 46, pp. 93102.

CHAMIZO, J. A. \& IZQUIERDO, M. (2006). Ciencia y contexto: una reflexión desde la filosofía. Alambique, 46, pp. 9-17.

GRUP SALTERS (2006). Física batxillerat. SaltersHorners. Edició Pilot. CDEC. Generalitat de Catalunya. Departament d'Ensenyament.

MEMBIELA, P.; PADILLA, Y. (eds.) (2005). Retos y perspectivas de la enseñanza de las ciencias desde el enfoque Ciencia-Tecnología-Sociedad en los inicios del siglo XXI. Vigo: Educación Editora.

PLANA, O. et al. (2005). La física Salters: un projecte de física per al batxillerat amb una orientació CTS. Enseñanza de las Ciencias, VII Congreso, n. extra.

SCIENCE EDUCATION GROUP (2001). Salters Horners Advanced Physics AS and A2. Students Book and Teacher and Technician Resource Pac. Londres: Heinemann.

SWINBANK, E. (2003). Salters Horners Advanced Physics Project: Un proyecto contextualizado para la enseñanza de la física. Alambique, 36, pp. 32-39.

Aquest treball s'ha desenvolupat en el marc d'una llicència d'estudis concedida pel Departament d'Educació de la Generalitat de Catalunya durant el curs 2007-2008. 